\title{
Türkiye Almanya ABD ve Avustralya Spor Sistemlerinin Bazı Değişkenler Açısından Karşılaştırılması
}

\author{
DOI: 10.26466/opus.585855
}

*

\author{
Hakan Sunay* $^{*}$ \\ * Doç. Dr, Ankara Üniversitesi, Spor Bilimleri Fakültesi, Gölbaşı/Ankara/Türkiye \\ E-Posta: hsunay@ankara.edu.tr \\ ORCID: $\underline{0000-0001-5139-1492}$ \\ Öz
}

Günümüzde çağdaş spor örgüt yapılanmasının ülkelerin gelişmişlik düzeyleri, kültürleri, nüfus demografik özellikleri gibi değişkenlerden etkilendiŭi kabul edilmektedir. İ̧ste bu etkiyi belirlemiş ve ayn zamanda sporda katılımı sağlamış ve sporda başarılı olmuş ülkeler arasından; Almanya, $A B D$ ve Avustralya ile Türkiye'nin "Spor Sistemlerinin" incelenerek karşılaştırılması önem taşımaktadır. Bu çalışmanın amacl; Almanya, ABD ve Avustralya'daki spor teşkilatlanması ve organizasyonel yapısı, spor finansmani, spora katılımı ve spor politikası incelenerek, spor sistemine yönelik bu uygulamaların Türkiye ile benzerlik ve farklılıkların belirlemektir. Bu araştırmada verilerin toplanmasında belgesel tarama tekniği kullanılmıştır. Almanya, ABD ve Avustralya ile ilgili veriler, bu ülkelerin resmi genel ăg (web) sitelerinden ve kitaplardan elde edilmiştir. Karşılaştırmal çalışmaların kendine özgü analiz yöntemlerine uygun olarak benzerlik ve farkllliklar analiz edilmiştir. Araştırma sonucunda; ̈̈lkelerin bazı değişkenlere göre spor sistemlerinde farklı uygulamaları olduğu tespit edilmiştir. ABD, Almanya ve Avustralya gibi sporda gelişmiş ülkelerin spor sistemlerinin kısmen ya da tamamının devletin gözetiminde olduğu ancak sorumluluğu yerel yönetimler ile özerk yapıda örgütlenen spor kuruluşlarına devrettikleri, ülkemizde ise spor sisteminin tamamen devletin kontrolünde olduğu belirlenmiştir.

Anahtar Kelimeler: Karşılaştırmalı spor sistemleri, Spora katılım, Spor finansmanı, Spor politikaSl 


\title{
Comparison of Sports Systems for Some Variables in Turkey Germany USA and Australia
}

*

\begin{abstract}
It is accepted today that the structure of contemporary sports organization is influenced by variables such as development levels, cultures and demographic characteristics of the countries. This is among the countries that have identified this effect and at the same time have achieved sport participation and the sport is successful; It is important to examine and compare "Sports Systems" of Germany, USA and Australia with Turkey. The purpose of this study is; Sport organization and organizational structure in Germany, USA and Australia, sport financing, sport participation and sport policy are examined and the similarities and differences of these applications for sport system with Turkey are determined. In this study, documentary scanning technique was used to collect data. Data on Germany, the United States and Australia have been obtained from official public web sites and books of these countries. Similarities and differences have been analyzed in accordance with the specific analysis methods of comparative studies. Similarity and differences have been revealed as a result of the comparison, and suggestions have been made taking into account the practices in Turkey. As a result of the research; it has been determined that the countries have different applications in sport systems according to some variables. The sporting systems of developed countries such as the USA, Germany and Australia are part or all under the control of the state. But it has been determined that responsibility is transferred to local governments and sports organizations organized in an autonomous structure and in Turkey sporting system is completely controlled by the state.
\end{abstract}

Keywords: Comparative sports systems, Participation in the sport, Sports financing, Sport policy. 


\section{Giriş}

Günümüzde spor bir yaşam tarzı haline gelmiştir. Sporun bireylerin yaptığı fiziksel ve zihinsel aktivite olması dışında bir de örgütsel yapısı vardır. Spor politikalarının ulusal ve uluslararası spor yapılanmaları üzerindeki etkisi, spor organizasyonlarının ve spor ekonomisinin öneminin artması bu alanda da yönetim ve organizasyon anlayışının gelişmesine yol açmıştır. Ülkelerin spor yönetimleri, kendi kültürel gelişimleri ile vatandaşlarının serbest zaman değerlendirmesi, eğlence anlayışları ve sportif performanslarının arttırılması ihtiyacı doğrultusunda şekillenir. Günümüzde çağdaş spor örgüt yapılanması ülkelerin gelişmişlik düzeyi, kültürleri, demografik özellikleri gibi değişkenlerden etkilenebilmektedir. (Ekmekçi, 2010). İşte bu etkiyi belirlemiş ve sporda başarılı olmuş ülkeler arasından; Almanya, ABD ve Avustralya ile Türkiye'nin "Spor Sistemlerinin" karşılaştırılması önem taşımaktadır. Karşılaştırma, düşünceyi geliştirmek için kullanılan bir yöntemdir. Sistemlerin karşılaştırmalı olarak incelenmesi, toplumlara kazandırdığı düşünce stili olan bir şeyin diğerine üstünlüğünün ya da ondan düşüklüğünün gösterilmesi durumu ile bir şeyin daha iyi/kaliteli olduğu kanıtlanmış bir şeyle karşılaştırılması (Sunay, 2017) olup, onun geliştirilmesi için gerekli boyut ya da öğelerinin gösterilmesidir. Spor sistemlerinin karşılaştırmalı olarak incelenmesinin yararları; farklı kültürlerin ve farklı spor sistemlerinin tanınmasını ve karşılaştırılmasını sağlar ve globalleşmeyi destekler. (Sutton, Post, Merkxi ve diğerleri, 2006).

Karşılaştırmalı araştırma sosyal bilimlerde kullanılan ve farklı ülke veya kültürler arasında karşılaştırma yapmayı amaçlayan bir araştırma yöntemidir. Dolayısıyla uluslararası karşılaştırmalar, sporda uygulanan farklı sistemlere ilişkin tercihlerin görülmesi ve belirlenmesi açısından oldukça önemlidir. Bu çalışma ile incelenen ülkelerin spor yönetim sistemlerine ilişkin organizasyonel yapı, spor finansmanı, spora katılım ve spor politikası incelenmiştir. Bu çalışmanın amacı; ABD, Almanya ve Avustralya'daki spor sistemine yönelik uygulamaların Türkiye ile benzerlik ve farklılıklarını incelemektir. 


\section{Alt Amaçlar}

1. Karşılaştırılan ülkelerdeki spor yönetim sistemlerine ilişkin organizasyonel yapı nasıldır? Ülkelerde sporcu nasıl yetiştirilmektedir? Aradaki benzerlikler ve farklılıklar nelerdir?

2. Karşılaştırılan ülkelerde sporun finansmanı nasıl sağlanmaktadır? Aradaki benzerlikler ve farklılıklar nelerdir?

3. Karşılaştırılan ülkelerdeki spor politikası nedir? Aradaki benzerlikler ve farklılıklar nelerdir?

4. Karşılaştırılan ülkelerde spora katılım nasıl sağlanmaktadır? Aradaki benzerlikler ve farklılıklar nelerdir?

\section{Yöntem}

$\mathrm{Bu}$ araştırma, bir karşılaştırmalı spor yönetimi araştırmasıdır. Karşılaştırmalı araştırmalarda kullanılan farklı yaklaşımlar vardır. Bunlar yatay, dikey, problem çözme, tanımlayıcı, açıklayıcı ve değerlendirici yaklaşımlardır. Yatay yaklaşımda sistemlerin ayrı ayrı ve birlikte tüm unsurları incelenir. Dikey yaklaşımda, incelenen sistemin tarihi evrimi izlenir (Türkoğlu,1998). Tanımlayıcı yaklaşımda ise konu ile ilgili literatür incelenir, spor sistemleri arasındaki benzerlikler ve farklılıklar karşılaştırılır. $\mathrm{Bu}$ araştırmada tanımlayıcı yaklaşımla beraber kısmen dikey yaklaşım, ülkelerin spor sistemlerinin karşılaştırılması olması nedeniyle de yatay yaklaşım kullanılmıştır. Araştırma, Avrupa Birliği'ne üye ülkelerden Almanya ile Amerika Birleşik Devletleri ve Avustralya'daki spor sistemine ilişkin bazı uygulamaların incelenmesi ve Türkiye' deki uygulamalarıyla karşılaştırılması ile sınırlıdır. Araştırma, elde edilen kaynaklar ve yazılı dokümanlarla sınırlıdır.

\section{Verilerin Toplanması ve Veri Kaynakları}

$\mathrm{Bu}$ araştırmada verilerin toplanmasında belgesel tarama tekniği kullanılmış, elde edilen dokümanların incelemesi yapılmıştır. Var olan kayıt ve belgeleri inceleyerek veri toplamaya belgesel tarama denir. Belgesel tarama, belli bir amaca dönük olarak, kaynakları bulma, okuma, not alma ve değerlendirme işlemlerini kapsar (Karasar, 2005; Erkuş, 2005). 
Belgesel tarama, hemen her araştırma için kaçınılmaz olan bir veri toplama tekniğidir. (Madge, 1965; Balc1, 2006). Belgelerin varlığ1 kadar, onlardan yararlanabilmek de önemlidir. Bilgide birikim ve süreklilik, belgelerle sağlanır. (Yıldırım ve Şimşek, 1999). Veri toplarken Türkiye, Almanya, $A B D$ ve Avustralya'nın genel spor sistemleri ve bu ülkelerde uygulanan spora ilişkin finansal destek (spor finansmanı) spora katılım, uygulanan spor politikalarına ilişkin (kitap, tez, makale, dergi, kalkınma planları gibi) bilimsel kaynaklardan yararlanılmıştır. Ayrıca veriler, ülkelerin resmi genel ağ (web) sitelerinden elde edilmiştir. Bu çalışmada Patton (1987) tarafından geliştirilmiş olan "tipik durum örneklemesi" kullanılmıştır. Tipik durum örneklemesinde amaç, tipik durumları seçerek evrene genelleme yapmak değildir. Amaç, belli bir alan hakkında fikir sahibi olmak veya bu alan, konu, uygulama veya yenilik konusunda yeterli bilgi sahibi olmayanları bilgilendirmektir.

\section{Verilerin Analizi}

Araştırma için elde edilen veriler, betimsel analiz yaklaşımında belirtilen amaçlar doğrultusunda, benzerlik ve farklılıklar analiz edilerek karşılaştırılmıştır (Yıldırım ve Şimşek, 2003).

\section{Bulgular ve Yorumlar}

Bu bölümde Türkiye Almanya $A B D$ ve Avustralya Spor Sistemlerinin karşılaştırılmasına ile ilişkin dört değişken için elde edilen bulgular tablolaştırılarak yorumlanmıştır. Elde edilen bulgulara ilişkin değişkenler:

1. Spor sistemlerinin yapısına ilişkin sporun üst yönetimlerinin teşkilatlanmasi

2. Spor sistemi içerisinde ülkelerin spora finansal destek uygulamaları

3. Spor sistemi içerisinde ülkelerin spora katılımları

4. Spor sistemleri karşılaştırılan ülkelerin spor politikaları 


\section{Spor Sistemlerinin Yapısına İlişkin Sporun Üst Yönetimlerinin Teşkilat- lanmasi}

Spor teşkilatları; spora ilişkin amaçlar doğrultusunda, geniş kapsamlı bir işin ya da işlerin görülmesi için kurulan spor hizmet kuruluşlarıdır.

Tablo 1. Spor sisteminin yapısına ilişkin sporun üst yönetimin teşkilatlanmasının görünümü

\begin{tabular}{llll}
\hline Almanya & ABD & Avustralya & Türkiye \\
\hline $\begin{array}{l}\text { Devlet; (içişleri } \\
\text { bakanlığı) ve }\end{array}$ & -Hükümet, ABD'de her & -Avustralya federal hükü- & -Türkiye'de \\
16 & seviyede "müdahaleci & metinin sporun gelişiminde & Devlet sporun üst \\
olmayan" bir yaklaşım & sorumluluğu & yönetiminde \\
federal bölge & benimsenir. -Sporun & vardır. & etkilidir. \\
,yerel yönetim & yapılandırılmasında & -Mahalli kuruluşlar tara- & Türkiye'de \\
seviyesinde & ağırlılı olarak "serbest & fından gerçekleştirilen spor & sporun Üst \\
"uzman spor & piyasa" (*) etkilidir. & aktivitelerine & yönetimi \\
ofisleri" etkili- & -ABD'de sporun yapı- & hükümet ve eyalet & "Gençlik ve Spor \\
dir. & lanması 3 yolla gerçekle- & yönetimleri & Bakanlı̆̆'dır". \\
& şir; & "sponsor desteği" & -Sporun organizasyonel \\
& 1.Profesyonel spor, & sağlamaktadır. & yapısında; \\
& 2.Üniversitesporu, & "Avustralya "Spor & Spor Genel \\
& 3.Okullar arası yerel spor & Komisyonu & Müdürlüğï, Spor fede- \\
& yarışmalarıdır. & (ASC)"devlet & rasyonları ve Spor \\
& & adına sporu yönetir & kulüpleri etkilidir. \\
\hline
\end{tabular}

(*)Sportif faaliyetlerin tam rekabet şartları içinde tarafların karşılıklı olarak anlaşmasıyla belirlendiği, arz ve talebe devlet tarafindan müdahale yapılmayan, sporda eğitim, sosyal ve ekonomik uygulamaların serbestçe yapılabildiğ i piyasayı tanımlar.

Günümüzde spor yönetiminin üst kuruluşu olarak bilinen; Uluslararası Olimpiyat Komitesi, Uluslararası Paralimpik Komitesi, Uluslararası Futbol Federasyonu, Uluslararası Basketbol Federasyonu gibi sporu uluslararası alanda yöneten hükümetler dışı kuruluşlar, her ülkenin uyması ve uygulaması gereken temel kuralları oluşturmuştur. Ulusal spor teşkilatları da söz konusu temel kurallar çerçevesinde ülke sporunu yönetirler. Bu devlet eliyle yapılabildiği gibi özerk kurumlarla da gerçekleşebilmektedir. İşte bu çeşitliliğin uygulandığı örneklerin karşılaştırıldığ çalışmada ülkelerin spor sisteminin yapısına ilişkin sporun üst yönetimin teşkilatlanmasının görünümü Tablo 1'de görülmektedir.

Tablo 1'de görüldüğü üzere, spor sisteminin yapısına ilişkin sporun teşkilatlanması; Almanya'da devlet, eyaletler ve yerel yönetim seviyesinde "uzman spor ofisleri" etkilidir (Petry and Hallmann, 2013; Breuer ve 
ark.,2015). ABD’de devlet kontrolünde serbest piyasa etkilidir. Hükümet, ABD'de spora her seviyede "müdahaleci olmayan" bir yaklaşım benimsemektedir. ABD'de sporun yapılanması 3 yolla gerçekleşir; 1.Profesyonel spor, 2.Üniversite sporu, 3.Okullar arası yerel spor yarışmalarıdır. Söz konusu 3 yapılanmada da devlet doğrudan müdahaleci olmaz. Örneğin: yetişkin beysbol ligini (MBL) beysbol derneği, Ulusal basketbol derneği (NBA) basketbol ligini organize eder (Ruseski and Razavilar, 2013). Avustralya'da devlet sponsorluğunda "Avustralya Spor Komisyonu" arac1lığ1 ile eyaletler sponsor desteği sağlamaktadırlar. Avustralya'da sporu, Avustralya "Spor Komisyonu (ASC)" devlet adina yönetir (Cuskelly ve ark.,2013). Türkiye'de ise Gençlik ve Spor Bakanlığı Koordinatörlüğünde spor federasyonları ve spor kulüpleri tarafından yürütülmektedir.

\section{Spor Sistemi İçerisinde Ülkelerin Spora Finansal Destek Uygulamalarn}

Spor hizmetlerinin nitelikli olarak sürdürülebilmesi için ülkelerin politikaları doğrultusunda spor etkinliklerine ayırdıkları finansal (bütçe) destek uygulanabilirliği ve şekliyle oldukça önemlidir.

Tablo 2. Ülkelerin spor sistemi içerisinde spora finansal destek uygulamalarııın görünümü

\begin{tabular}{|c|c|c|c|}
\hline Almanya & ABD & Avustralya & Türkiye \\
\hline $\begin{array}{l}\text {-Amatör spor sivil } \\
\text { toplum örgütlerince } \\
\text { örgütlenmişlerdir. } \\
\text { Gelirler üye aidatla- } \\
\text { rı ve sponsorluk } \\
\text { uygulamaları ile } \\
\text { elde edilir. } \\
\text { (Petry and Hallmann, } \\
\text { 2013) }\end{array}$ & $\begin{array}{l}\text {-ABD, spora finansal } \\
\text { destek konusunda "mü- } \\
\text { dahaleci olma- } \\
\text { yan"(handsoff approach) } \\
\text { bir yaklaşım içerisindedir. } \\
\text {-ABD'de her konuda } \\
\text { olduğu gibi "serbest } \\
\text { piyasa ekonomisi" } \\
\text { geçerlidir. } \\
\text { (Ruseski and } \\
\text { Razavilar, 2013) }\end{array}$ & $\begin{array}{l}\text {-Spora finansal destek, devlet } \\
\text { tarafından sağlanır. Federal } \\
\text { hükümet bütçesinden her yıl } \\
\text { "Toplumsal } \\
\text { Rekreasyon ve Spor Tesisleri } \\
\text { Programı" doğrultusunda } \\
\text { planlanmaktadır. } \\
\text {-Avustralya'da kitle sporuna } \\
\text { ve elit sporu geliştirmede } \\
\text { hükümet desteği yapılmakta- } \\
\text { dır. } \\
\text { (Cuskelly ve ark.,2013) }\end{array}$ & $\begin{array}{l}\text {-Türkiye'de spora } \\
\text { devlet desteği yapıl- } \\
\text { maktadır. Destek, } \\
\text { spor federasyonların } \\
\text { a doğrudan, özerk } \\
\text { futbol federasyonuna } \\
\text { ise dolaylı olarak } \\
\text { yapılmaktadır } \\
(A k, 2017)\end{array}$ \\
\hline
\end{tabular}

$\left.{ }^{*}\right)$ Ekonomik faaliyetlerin tam rekabet şartları içinde serbestçe yapılabildiği, ekonomik sorunların çözümünün devletin ekonomiye müdahalesiyle değil fiyat mekanizması aracıllğ̆ ile gerçekleştirildiği ekonomik şartlardır.

Öyle ki spor organizasyonları ile spora katılıma ilişkin etkinliklerin finansal destek olmadan yapılması neredeyse imkânsızdır. Spor sistemi 
içerisinde finansal destek uygulamalarının görünümü Tablo 2'de verilmiştir.

Tablo 2'de görüldüğü gibi, ülkelerin spor sistemi içerisinde spora finansal destek uygulamasında; Almanya'da devlet spora kısmen finansal destek verirken, $\mathrm{ABD}^{\prime}$ de devlet müdahaleci olmayıp, spora finansal destekte serbest piyasa ekonomisi ${ }^{(*)}$ şartları geçerli olmaktadır. Öyle ki $\mathrm{ABD}^{\prime}$ de her organizasyon kendi finansmanını kendisi sağlar. Almanya'da Alman hükümeti spora maddi destek sağlar. Spor kulüpleri devlete ya da yerel yönetimlere ait spor tesislerini kullanırlar. Avustralya ve Türkiye'de ise devlet spora finansal olarak destek olmaktadır. Avustralya'da finansal destek, "Avustralya Spor Komisyonu (ASC)"spor için finansal kaynakla sağlanırken, Türkiye'de destek, spor federasyonlarına doğrudan, özerk futbol federasyonuna ise dolaylı olarak yapılmaktadır.

\section{Spor Sistemi İçerisinde Ülkelerin Spora Katılımı}

Ülkelerin oluşturdukları spor politikası gereği öncelikli hedefler arasında her zaman vatandaşlarına spor imkânları sunarak spor yapmalarını sağlamak olmaktadır. Öyle ki kitlelerin spor yapmasındaki başlıca amaç; eğlenmek, dinlenmek, yeni dostlar edinmek, günlük yaşamın stresinden uzaklaşmak, dolayısıyla fiziksel ve ruhsal sağlığı korumaktır. Önemli olan da sporun bir yaşam biçimi olarak sürdürülebilir hale gelebilmesidir. Nitekim günümüzde de sağlıklı bir toplumun önemi giderek artmaktadır. Hareketsizliğe bağlı obezite, diyabet, kalp ve damar hastalıkları gibi ölümcül hastalıkların giderek artması özellikle de batılı toplumların gelecek yıllarda uğraşması gereken önemli sorunlardandır. Onuncu Beş Yıllık Kalkınma Planı Spor Özel İhtisas Komisyonu Raporunda; ülkemizde kesin veriler olmasa da nüfusun yaklaşık \%33 kadarının obez olduğu, bu sayının önümüzdeki 10 yılda daha da artacağı öngörülmektedir (10. Beş Yıllık Kalkınma Planı Spor ÖİK Raporu, 2013). Öte yandan toplumsal sağlı̆ıı yanı sıra söz konusu hastalıkların ve hareketsizliğin ortaya çıkardığı üretim gücünde düşme ile ağır bütçeli ilaçların devletlerin önemli bir sorunu olduğu bir gerçektir. Oysa spor yapan bir toplum bireysel ve toplumsal sağlık ve üretimin niteliğini düşürmeme, koruma ve geliştirme açısından toplumsal düzenlemeleri gerektirmektedir. Ayrıca, kitle sporunun yaygınlığı beraberinde çok sayıda elit sporcu yetişme- 
si için temel koşullardan biridir. Spor sistemleri karşılaştırılan ülkelerin "spor branşlarına katılımlarına" ilişkin veriler, Tablo 3 ve Tablo 4'de gösterilmiştir.

Tablo 3. Spor sistemleri karşılaştırılan ülkelerin spor branşlarına katılımlarııın görünümü

\begin{tabular}{|c|c|c|c|}
\hline anya & ABD & Avustralya & Türkiye \\
\hline 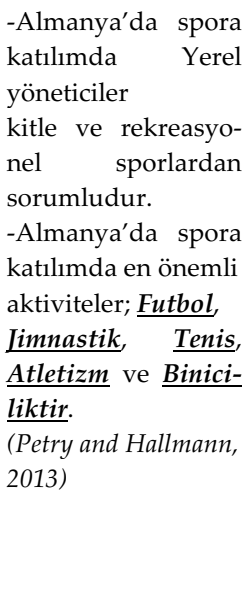 & 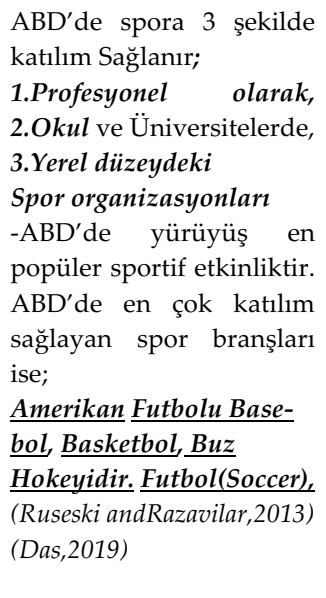 & $\begin{array}{l}\text {-Avustralya'da Rekre- } \\
\text { asyonel sportif aktivi- } \\
\text { teler spora katılımın ilk } \\
\text { sırasındadır. } \\
\text {-Avustralya'da } \\
\text { Spora katılım sağlayan } \\
\text { spor branşları ise; } \\
\text { Futbol, Tenis, } \\
\text { Basketbol, } \\
\text { Bisiklet, Yüzmedir. } \\
\text {-"Avustralya } \\
\text { Spor Geliştirme Gru- } \\
\text { bu” ise halkın spora } \\
\text { katılımının artmasın- } \\
\text { dan sorumludur. } \\
\text { (Cuskelly ve ark.,2013) }\end{array}$ & 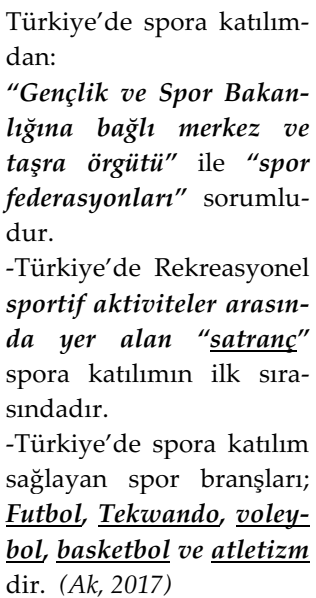 \\
\hline
\end{tabular}

Tablo 4. Spor sistemleri karşılaştırılan ülkelerin spor branşlarına katılımlarının sayısal görünümü

\begin{tabular}{|c|c|c|c|c|}
\hline $\begin{array}{l}\text { Spor Branşları / } \\
\text { Ülkeler }\end{array}$ & ABD (2019) $\left(^{*}\right)$ & $\begin{array}{l}\text { Almanya } \\
(2013) \\
(* * * * *) \\
\end{array}$ & $\begin{array}{l}\text { Avustralya } \\
(2013) \\
(* * * * *)\end{array}$ & $\begin{array}{l}\text { Türkiye } \\
(2016) \\
(* * * *)\end{array}$ \\
\hline Amerikan Futbolu & (1) & & & 9.701 \\
\hline Atletizm & & $885.664(4)$ & 91.200 & $196.489(5)$ \\
\hline Badminton ${ }^{(* * *)}$ & $(10)$ & 216.516 & 47.700 & 72.169 \\
\hline Basebol / Softbol & (2) & & & \\
\hline Basketbol & (3) & 190.152 & $403.500(3)$ & $222.796(4)$ \\
\hline Binicilik & & $737.103(5)$ & 87.600 & 4.435 \\
\hline Bisiklet & & 134.816 & $264.000(4)$ & 24.556 \\
\hline Buz Hokeyi & (4) & & & 6.580 \\
\hline Golf & $(7)$ & & & 6.828 \\
\hline Güreş ${ }^{\left({ }^{* * * *}\right)}$ & $(8)$ & 66.605 & Çok düşük $\left(^{* *}\right)$ & 112.109 \\
\hline Jimnastik ${ }^{(* * *)}$ & & $4.972 .043(2)$ & 35.200 & 55.287 \\
\hline Futbol (Soccer) ${ }^{(* * *)}$ & (5) & $6.756 .562(1)$ & 593.800 (1) & $615.297(1)$ \\
\hline
\end{tabular}




\begin{tabular}{lllll} 
Hentbol & & $84 * * *)$ & Çok düşük $\left(^{(* *}\right)$ & 103.710 \\
\hline Motor Sporları & $(9)$ & & & 5.762 \\
\hline Tekwondo & $(11)$ Martial Arts & 55.376 & 178.500 & $\mathbf{3 6 2 . 9 2 7 ~ ( 2 )}$ \\
\hline Tenis & $(6)$ & $\mathbf{1 . 5 5 9 . 4 1 2 ( 3 )}$ & $\mathbf{4 1 9 . 2 0 0 ~ ( 2 )}$ & 30.663 \\
\hline Voleybol & & 481.442 & 146.600 & $\mathbf{2 4 3 . 4 3 6 ( 3 )}$ \\
\hline Yüzme & & 575.509 & $\mathbf{2 2 2 . 8 0 0 ~ ( 5 )}$ & 150.247 \\
\hline
\end{tabular}

$\left({ }^{*}\right)($ Das, 2019) https://sportsshow.net.com/most-popular-sports-in-americal

$\left.{ }^{* *}\right)$ Sayısal olarak çok düşük olduğundan raporlandırılmamıştır.

$\left.{ }^{* * *}\right)($ Yüce ve Sunay, 2013)

$\left(^{(* * * *}\right)\left(\right.$ Ak, 2017) $\left(^{(* * * *)}\right)\left(\right.$ Petry and Hallmann, 2013) $\left(^{* * * * *}\right)($ Cuskelly ve ark., 2013)

Tablo 3'de görüldüğü gibi, spor sistemleri karşılaştırılan ülkelerin spora katılımlarında; Almanya'nın spor sistemi; hem kamusal hem de bölgesel yapısı ile kendine has özelliklere sahiptir. Almanya'da devlet üst düzey sporu organize ederek, yerel yöneticilerin kitle ve rekreasyonel sporlardan sorumlu olurken, ABD'de devlet, özellikle profesyonel spora müdahaleci olmayıp, kitle ve rekreasyonel sporları teşvik etmektedir. Avustralya'da devlet; Avustralya spor komisyonu aracılı̆̆ ile hem elit hem de halkın spora katılımından sorumlu olurken, Türkiye'de devlet, elit ve halkın spora katılımından doğrudan sorumlu olmaktadır.

Tablo 4'de görüldüğü gibi, karşılaştırılan ülkelerin (Almanya, Avustralya ve Türkiye) katıldıkları öncelikli sportif aktivitelerin başında futbol yer alırken, ABD'de öncelikli spor branşı Amerikan Futbolu olmuştur. İkinci öncelikli spor branşı ise ülkelere göre değişmektedir. ABD'de Basebol, Almanya'da Jimnastik, Avustralya'da Tenis, Türkiye'de ise Tekvando'dur (362.927). Üçüncü öncelikli spor branşları ülkelere göre farkl1lık göstermekle birlikte, hepsinde takım sporlarının lisanslı sporcu say1ları yüksek bulunmuştur. Karşılaştırılan ülkelerin federasyon bünyesinde teşkilatlanmış spor branşları yaklaşık 60-61 dir. Bu spor branşlarının bir kısmı olimpik ve paralimpik, bir kısmı da henüz olimpik ve paralimpik değildir. Bunun yanı sıra ülkelerde spor lisansı olmadan "Sağlık ve Spor Kulüplerine" üye olarak kitle sporuna (fiziksel aktiviteye) katılan çok sayıda insan bulunmaktadır. Ülkelerde kitle sporuna yönelik "sağlık ve spor kulüplerine" üye olarak spor yapanların sayısal verileri Tablo 5'de gösterilmiştir. 
Tablo 5. Ülkelerde kitle sporuna yönelik "sağlık ve spor kulüplerine" üye olarak spor yapanlarn sayısal verileri (2016)

\begin{tabular}{lllll}
\hline Ülkeler & Nüfus & $\begin{array}{l}\text { Sağlık ve Spor } \\
\text { Kulüp sayıs1 } \\
\mathbf{( * )}^{*}\end{array}$ & $\begin{array}{l}\text { Sağlık ve Spor } \\
\text { Kulüp Üye } \\
\text { sayıs1 }\left(^{*}\right)\end{array}$ & $\begin{array}{l}\text { Üye } \\
\text { sayısının } \\
\text { nüfusa oranı }\end{array}$ \\
\hline ABD (**) & 313.232 .044 & 29.890 & 50.000 .000 & $\% 16,0\left(^{(*)}\right.$ \\
\hline Almanya (***) & 82.302 .000 & 5.930 & 7.100 .000 & $\% 8,63^{(*)}$ \\
\hline Avustralya (***) & 22.268 .000 & Bilinmiyor & 5.232 .980 & $\% 23,5^{(* * *)}$ \\
\hline Türkiye & 79.814 .871 & 1.340 & 420.000 & $\% 0,533^{(*)}$ \\
\hline
\end{tabular}

(*) Bilkent Holding (2016) “Dünyada Bazı Ülkelerdeki Sağlık ve Spor Kulüplerine

Üyelerin Kulüp Sayısı Ülke Nüfuslarna oranı" Sport International Bilkent Holding

Ankara $\left(^{* *}\right)\left(\right.$ Ruseski and Razavilar, 2013) $\left.{ }^{* * *}\right)$ Petry and Hallmann, 2013)

${ }^{* * * *}$ Cuskelly, G., Wicker, P. And Wendy O'Brien (2013)

Tablo 5'de görüldüğü gibi ülkelerde lisanslı olarak spor yapanların yanı sıra kitle sporuna yönelik özel sağlık ve spor kulüplerinde önemli sayıda sportif aktiviteye katılanların bulunduğu görülmektedir. Sağlık ve Spor kulüplerinde sportif aktivitelere katılanlar arasında ülkelere göre farklılıklar saptanmıştır. Avustralya' da yaşayanların sağlık ve spor kulüplerine yoğun olarak katılırlarken, ABD'de yaşayanların \%16,0'sının bu tür kulüplere devam ettiği görülmektedir. Türkiye'de ise bu oran oldukça düşük düzeyde $(\% 0,53)$ olduğu görülse de ülkemizde son yıllarda gelişen (sağlık ve spor kulübü) fitness sektörü yaklaşı 850 milyon liralık ekonomik büyüklüğü ile Avrupa sıralamasında \%4 'lük bir pazar payına ulaşmıştır (Ak, 2017). Öte yandan karşılaştırılan ülkelerin üçünde spora katılımda 1. Sırada yer alan futbol branşına ilişkin Türkiye ve diğer ülkelerdeki katılım verileri Tablo 6 ve 7'de detaylı olarak gösterilmiştir.

Tablo 6. Türkiye'de Futbol branşına lisanslı olarak "katılıma" ilişkin sayısal veriler (2017) $(A k, 2017)$

\begin{tabular}{lccll}
\hline Sporcu Sayısı (Kurum) & Kadın & Erkek & Toplam (Lisanslı) & Toplam (Faal) \\
\hline $\begin{array}{l}\text { Türkiye Futbol } \\
\text { Federasyonu (TFF) }\end{array}$ & 5.522 & 614.210 & 619.732 & $\begin{array}{l}\text { Nüfusa göre } \\
\text { Türkiye'de futbola katılım } \\
\text { Lisanslı.77 }\end{array}$ \\
\hline
\end{tabular}

Spor sistemleri karşılaştırılan ülkelerin "Futbol" branşına katılımlarına ilişkin sporcu sayıları ve nüfusa oranları Tablo 7' de görülmektedir. 
Tablo 7. Karşılaştırılan ülkelerin "Futbol" branşına ilişkin sporcu sayıları ve nüfusa oranlart

\begin{tabular}{llll}
\hline Ülkeler / Futbola katılım & Genel nüfus & Futbolcu sayısı & $\begin{array}{l}\text { Futbola katılanların } \\
\text { genel nüfusa oranı }\end{array}$ \\
\hline ABD $^{*}$ (American football) & 313.232 .044 & 13.600 .000 & $\% 4.34$ \\
\hline Almanya ${ }^{* *}$ & 82.302 .000 & 6.756 .562 & $\% 8.20$ \\
\hline Avustralya ${ }^{* * *}$ & 22.268 .000 & 593.800 & $\% 2.67$ \\
\hline $\begin{array}{l}\text { Türkiye } \\
\text { (2018 nüfus verilerine göre) }\end{array}$ & 82.003 .882 & $\begin{array}{l}619.732 \\
* * * *\end{array}$ & $\% 0.77$ \\
\hline
\end{tabular}

${ }^{*}$ Das,2019 ${ }^{* *}$ Petry and Hallmann, 2013). ${ }^{* * *}$ Cuskelly ve ark., $2013{ }^{* * * *}(A k, 2017$, s.123)

Türkiye dâhil Avustralya ve Almanya'da 1. Amerika Birleşik Devletlerinde 3. Katılım sırasına sahip ve oldukça eski bir tarihi geçmişe sahip olan Futbol, dünyanın en popüler spor dalından biridir. Yüzyılı aşkın bir zamandır oynanan modern futbol, İlk olarak 19.yüzyılın başlarında kurallar konarak oynanmaya başlamıştır (Cuskelly ve ark., 2013), (Petry and Hallmann, 2013). Futbol Dünyada kendine özgü bir ekonomisi olan bir spor branşıdır. Bu özelliği ile diğer spor branşlarından ayrılmaktadır. Ekonomik etkinliği ile üst düzeyde oynanan futbol, dünyada büyük bir çoğunlukla profesyonel olarak yapılmaktadır. Bu özelliği ile de ülkelerdeki spora katılımda 1. Sırada olması doğal kabul edilebilir. Burada spora katılımda 2. Siralarda farklılıklar bulunmaktadır. Bunlardan ABD'de 1. Sırada Amerikan Futbolu, 2.sırada Basebol sporu ile katılım gerçekleşirken, (Das, 2019) Almanya'da 2. Sırada Jimnastik, Avustralya'da Tenis, Türkiye'de ise Tekvando yer almıştır. Sıralamada üst sıralarda yer alan spor branşları ülkelerin beğenilerini ve ilgilerini de ortaya koymaktadır. Ancak Türkiye'de katılımda 2. Sırada Tekvandonun yer alması ilginçtir. Türkiye'de spor kültürünü ve gelenekselliği yansıtan uluslararası spor organizasyonlarında kısmen başarılı da olmuş; Güreş, Okçuluk ve Halter gibi spor branşları ilk beş sırada yer almazken, Tekvandonun 2. Sırada, Voleybolun 3. Sırada katılım sağlaması ile ağırlıklı olarak ülkenin mücadele sporları anlayışına yöneldiği yorumları yapılmıştır (Ak, 2017). Kuşkusuz uzak doğu sporlarına doğru bir yöneliş izlenmekte ise de Türkiye'de Futboldan sonra, Voleybol, Basketbol gibi takım sporlarına katıl1min azımsanmayacak bir oranda olduğu söylenebilir. Uzak doğu sporlarına doğru yönelişin bir nedeni de aksiyon filmlerinin artması ile müca- 
dele sporlarının çeşitliliğinden ve kursların yaygın oluşundan kaynaklanıyor olabilir. Spor sistemleri karşılaştıılan ülkelerin "spora katılımlarına" ilişkin sayısal verilerin, genel nüfus oranlarına göre karşılaştırılması ise Tablo 8' de görülmektedir.

Tablo 8. Spor sistemleri karşılaştırılan ülkelerin tüm spor branşları için "spora katılımlarına" ilişkin sayısal veriler (*)

\begin{tabular}{llllll}
\hline Ülke & $\begin{array}{l}\text { Kadın } \\
\text { Nüfus }\end{array}$ & $\begin{array}{l}\text { Erkek } \\
\text { Nüfus }\end{array}$ & $\begin{array}{l}\text { Toplam } \\
\text { Nüfus }\end{array}$ & $\begin{array}{l}\text { Lisanslı } \\
\text { spor yapan } \\
\text { nüfus }\end{array}$ & $\begin{array}{l}\text { Lisanslı } \\
\text { Sporcuların } \\
\text { nüfusa oranı (\%) }\end{array}$ \\
\hline A.B.D & 158.947 .429 & 154.264 .615 & 313.232 .044 & 216.600 .000 & 69.2 \\
\hline Almanya & 41.962 .000 & 40.341 .000 & 82.302 .000 & 27.636 .026 & 33.6 \\
\hline Avustralya & 11.176 .000 & 11.093 .000 & 22.268 .000 & 14.402 .400 & 64.7 \\
\hline $\begin{array}{l}\text { Türkiye } \\
\text { (2018) }\end{array}$ & $\mathbf{4 0 . 8 6 3 . 9 0 2}$ & $\mathbf{4 1 . 1 3 9 . 9 8 0}$ & $\mathbf{8 2 . 0 0 3 . 8 8 2}$ & $\begin{array}{l}\mathbf{5 . 9 9 5 . 9 7 3} \\
\text { (Lisansli) }\end{array}$ & $\mathbf{7 , 3}$ \\
& & & & $\begin{array}{l}\mathbf{3 . 1 1 3 . 4 6 6} \\
\text { (Faal) }\end{array}$ & \\
\hline
\end{tabular}

(*) Kaynak: Onuncu (10). Beş Yıllık Kalkınma Planı Spor ÖIKK Raporu, (2013).

Tablo 8'de görüldüğü gibi, karşılaştırılan ülkelerin tüm spor branşlarını içeren spora katılımlarına ilişkin sayısal istatistikî veriler; farklılık göstermektedir. ABD ve Avustralya'da lisanslı olarak spora katılanların oranı oldukça yüksek olduğu belirlenmiştir. Bu oranın söz konusu bu ülkelerde rekreatif olarak (haftada 2 defa düzenli olarak açık havada koşanlar) sportif aktivitelerine katılanlar da dahil edildiğinde daha da yükseldiği vurgulanmaktadır. Avustralya sporu yüksek katılımlı bir alan (Aktif Avustralya) haline getirmeye çalışan bir sisteme sahiptir. Bu sistemin düzenli uygulanması ile Avustralya nüfusunun \%93,0'ünün spor ve rekreaktif etkinlikler içerisinde olduğu vurgulanmıştır. Bu oranı yakalamada etkili olan uygulamaların başında Okullarda Spor Programının uygulanması, Taban Kesimin Spora Katılımı ve Kadınların Spora Katılımı programları gelmektedir. (Cuskelly, et al, 2013) (Ruseski and Razavilar, 2013) Almanya'da ise durum benzerdir spora katılım Almanya'da genel olarak \%63,6 iken lisanslı olarak \%33,6 dır (Tews, I H.,2006).

\section{Spor Sistemleri Karşılaştırılan Ülkelerin Spor Politikaları}

Politika; günümüzdeki ve gelecekteki kararlara yön verebilmek için bir- 
çok alternatif arasından seçilen belirli bir yol veya davranış tarzı olarak tanımlanırken, spor politikası ile de; sporun ilke ve hedefleri, bu hedeflere ulaşmadaki yol ve yöntemleri, alt yapı, tesis, araç-gereç ve eğitimöğretim anlayışı, ulusal ve uluslararası düzeyde spora bakış açısı, sporun örgütleniş ve uygulanış felsefesi anlaşılmaktadır (Hoye ve ark.,2015). Bu nedenle de ülke spor politikalarını oluşturmada belirleyici olan yazılı belgelerde olan yaklaşımlar ile belirlenmektedir. Özellikle de sporun devlet tarafından yönlendirildiği durumlarda ülke spor yönetiminin belirleyici unsuru olan anayasa, kanunlar, kalkınma ve hükümet programlarında ya da özel belgelerde ortaya konulmaktadır (Ak, 2017). Türkiye anayasasında spora yer veren az sayıda ülkelerden biridir. Spor yapma hakkı anayasa ile korunmasının yanı sıra spor açı bir şekilde anayasada yer alarak devletin yükümlülügünü de ortaya koymaktadır. Kaldı ki olimpik şartın 4. Maddesinde "spor yapmak bir insan hakkıdır. Her bireyin ihtiyaçlarıla doğru orantıda spor yapma olanağına sahip olması gerekir" biçiminde belirtilirken, bu madde ile bir devlet politikası olarak hükümetlere sporu yürütme yükümlülügü getirmektedir. Spora ilişkin tüm kurumların temel toplumsal işlevi insanların temel ihtiyaçlarını karşılamak olduğundan dolayı da çağımızın en önemli kurumlarından biri olan spor, uluslar arası alanda bir "insan hakkı" olarak tanımlamaktadır. Türkiye'de spor yapma hakkı anayasa ile güvence altına alınmıştır. Bu bağlamda devletin görevi sadece sporcuyu korumak değil, kitlelerin bu hakka erişimini sağlamak olarak da görülmelidir. Diğer bir deyişle devletin fiziksel, sosyal, zihinsel ve kültürel gelişimine katkıda bulunan sağlıklı toplumlar yaratmada önemli bir sosyal politikası olarak değerlendirilmelidir. Bu özellikleriyle spor, bir kamu hizmeti alanı olarak görülmektedir (Fişek, 1998). Spora önemli katkılar sağlayan ve Avrupa birliğinin önemli bir ülkesi olan Almanya, bağlı bulunduğu Avrupa Birliği spor konseyinin beyaz kitap olarak tanımlanan ana ilkeler yazılı belgesinde belirtilen spor tanımına $(\mathrm{Ak}, 2017)$ göre spor politikalarının geliştirilmesini sağlamıştır. Bu tanıma göre; 1. Kitle (rekreasyonel spor, herkes için spor) sporu, 2. Yarışma sporu olmak üzere iki temel alan ortaya çıkmaktadır. Ayrıca günümüzde özellikle de ekonomiye olan bağımlılıktan dolayı da temel spor politikalarının değerlendirilmesinde ki önemi göz ardı edilmemelidir. Özellikle de ABD 'de sporun yönetimi, ülkenin sosyo ekonomik yapısı ile benzerdir. Spor sistemleri karşılaştırılan ülkelerin 
"spor politikalarına" ilişkin veriler, Tablo 9'da gösterilmiştir.

Tablo 9. Spor sistemleri karşılaştırılan ülkelerin spor politikalarına ilişkin bulgular

\begin{tabular}{lllll}
\hline Almanya & ABD & Avustralya & Türkiye \\
\hline 1.Üst düzey (elit) & 1.Herkes için Spor & 1.Spora rekreatif amaçlı & 1.Sağlığın korunma- \\
yarışma sporu & (öncelik) & katılım programları öncelik- & sina yönelik tedbir- \\
2.Halkın & 2. ABD'de elit spo- & lidir. & ler sporun kitlelere \\
katıldığı & run & 2.Elit spor (ASC) aracilığı ile & yayılması 2.Başarılı \\
(kitle) sporu & gelişiminden özerk & yaptırılır & sporcuların korun- \\
& organizasyonlar & & ması (Anayasa \\
& sorumludur. & & M.59) \\
\hline
\end{tabular}

Tablo 9'da görüldüğü gibi, karşılaştııılan ülkelerin spor politikalarına ilişkin bulguların farklılık göstermektedir. Almanya' da sporun üst düzey (elit) yarışma sporu ile halkın katılım sağladığı kitle sporunun farklı sorumlu kurumlar tarafından yönetildiği, spor politikasının bu iki yapılandırma çerçevesinde gerçekleştirildiği gözlenmektedir. ABD'de spor politikasının benzer olduğu ancak uygulamada farklılıkların olduğu gözlenmektedir. Örneğin devletin spor politikasının uygulamalarında müdahaleci olmadığı ancak spora katılımlar için geniş fırsatlar sunulduğu belirlenmiştir. ABD'de öncelik 1.Herkes için Spor uygulamalarıdır. 2.Elit sporun gelişiminden ise özerk organizasyonlar sorumludur.

Avustralya'da spor politikasının uygulanmasında özerk kuruluşlara yetki verilerek sorumluluk paylaşılmıştır. Avustralya'da spora rekreatif amaçlı katılım programları önceliklidir. Elit spor ise Avustralya Spor Komisyonu (ASC) aracılığı ile yaptırılır. Avustralya'da 1972 öncesi Devletin katkısı azdır. 1972 sonrası Turizm ve rekreasyon Bakanlığı spora katkı vermeye başlamış, 1981 sonrasında da (elit sporda başarı için) "Avustralya spor enstitüsü" kurulmuştur. Mevcut yapı ve uygulamalarıyla karşılaştırılan 3 ülkede farklı uygulamaların olduğu belirlenmiştir.

Türkiye'de ise spor politikası her ne kadar belirlenmiş olsa da ülke spor politikasının uygulamasında kararsızlık yaşandığı, sağlığın korunmasına yönelik olarak kitle sporuna mı? Yoksa elit spora mı? Öncelik verileceği konusunda belirsizlik ve kararsızlık yaşandığı önemli bir gözlemdir. Kuşkusuz spor politikasının yönetilmesinde sosyal devlet anlay1şı dikkate alındığında sağlığın korunmasına yönelik uygulamaların ağırlık kazanması gerekirken, uluslararası politikalar ve ülke siyaseti açıla- 
rından elit sporu güçlendirerek ön plana çıkarma anlayışı da sürekli güncelliğini korumaktadır. İşte bu belirsizlik ve kararsızlığın giderilmesine yönelik her iki politikanın da bütünleşerek uygulanmasının doğru bir uygulama olacağı düşünülebilir (Ak, 2017).

Bu bağlamda hem sağlıklı bir toplum, hem de maddi kaynakların korunması için kitle sporu ya da herkes için spor ile elit sporu birlikte geliştirmeleri gerekmektedir.

\section{Sonuç ve Öneriler}

Bu bölümde, spor sistemleri karşılaştırılan ülkelerin elde edilen bulgular çerçevesinde belirlenen 4 değişkene göre sonuçlar belirtilmiştir.

\section{Spor Sistemlerinin Yapısına İlişkin Sporun Üst Yönetimlerinin Teşkilat- lanmasına İlişkin Sonuçlar;}

Almanya'da devlet, doğrudan sporu yönetmemektedir. Spor yönetimi ulusal düzeyde içişleri bakanlığı, 16 federal bölgede bölgesel spor federasyonları, yerelde ise spor dernekleri, spor kulüpleri tarafından teşkilatlanarak spor yönetilmektedir. $A B D^{\prime}$ de sporun yönetiminde Amerikan devleti (hükümeti) müdahaleci olmamaktadır. ABD'de sporun nasıl yapılandırılıp organize edildiğini belirlemek için ağırlıklı olarak "serbest piyasa" etkili olmaktadır. ABD'de sporun yapılanması 3 yolla gerçekleşir; 1.Profesyonel spor, 2.Üniversite sporu, 3.Okullar arası yerel spor yarışmalarıdır. Söz konusu 3 yapılanmada da devlet doğrudan müdahaleci olmaz. Avustralya'da ise sporun yönetimi paylaşımcı bir yaklaşımla gerçekleşmektedir. Öyle ki Avustralya'da devlet sporun tüm yollarını destekleyecek altyapı ve programlara yatırım yapar. Mahalli kuruluşlar tarafından gerçekleştirilen spor aktivitelerine hükümet ve eyalet yönetimleri "sponsor desteği" sağlamaktadır. "Avustralya Spor Komisyonu (ASC)" devlet adına sporu yönetir. Türkiye'de ise sporun yönetiminde devlet oldukça etkindir. Hükümet adına Gençlik ve Spor Bakanlığı, Spor Genel Müdürlüğü ve taşra teşkilatları ile spor federasyonları Anayasanın 58 ve 59 . Maddeleri ile ilgili yasalara dayanılarak sporu yönetirler. 


\section{Spor Sistemi İçerisinde Ülkelerin Spora Finansal Destek Uygulamalarn- na İlişkin Sonuçlar;}

Elit spora ve fiziksel aktiviteye katılımın arttırılmasına yönelik finansal destek sağlama anlayışı, günümüzde ülkelerin spor politikalarında önemli müdahale alanı haline gelmiştir (Hoye ve ark., 2015).

Almanya'da devlet asgari ölçüde spora finansal destek sağlarken amatör spor, sivil toplum örgütlerince örgütlenmişlerdir. Gelirlerini üye aidatlarından ve sponsorluk uygulamalarıyla elde etmektedirler. $A B D^{\prime}$ de devlet spora finansal destek konusunda müdahaleci olmamaktadır. ABD'de her konuda olduğu gibi sporda da serbest piyasa ekonomisi geçerlidir. ABD'de Her spor organizasyonu kendi finansmanını kendisi sağlamaktadır. Avustralya'da Spora finansal destek, devlet tarafından sağlanır. Hükümet bütçesinden her yıl "Toplumsal Rekreasyon ve Spor Tesisleri Programı" doğrultusunda planlanmaktadır. Avustralya'da kitle sporuna ve elit sporu geliştirmede hükümet desteği yapılmaktadır. Destek, Devlet adina hareket eden Avustralya "Spor Komisyonu (ASC)"aracılığı ile spor için finansal kaynak sağlar. Türkiye'de ise spora devlet desteği yapılmaktadır. Destek, spor federasyonlarına doğrudan, özerk futbol federasyonuna ise dolaylı olarak yapılmaktadır. Verilerden de anlaşılacağı üzere, genel olarak spora finansal destek sağlama noktasında devletin rolü bulunmaktadır. Ancak finansal destek sağlama yöntemi, incelenen ülkelere göre değişebilmektedir. Almanya ve Avustralya'da devletin spora finansal desteği dolaylı olarak sağlanırken, Türkiye'de spora finansal destek doğrudan sağlanmaktadır. ABD'de ise spora finansal destek olma konusunda devlet müdahaleci değildir. Özel kurum ve kuruluşlar, spora finansal destek sağlayabilmektedir.

\section{Spor Sistemi İçerisinde Ülkelerin Spora Katılımına İlişkin Sonuçlar;}

Almanya'da spora katılım Rekreasyonel sportif aktiviteler ile Futbol, Jimnastik, tenis, atletizm ve biniciliktir. ABD'de spora 3 şekilde katılım sağlanır; 1.Profesyonel olarak, 2.Okul ve Üniversitelerde, 3. Yerel düzeydeki spor organizasyonlar ile ABD'de yürüyüş en popüler sportif etkinliktir. ABD'de en çok katılım sağlayan spor branşları ise; Amerikan Futbolu, Basebol, Basketbol, Buz Hokeyi ve Futbol (soccer). Avustralya'da Rekreasyo- 
nel sportif aktiviteler spora katılımın ilk sirasındadır. Avustralya'da spora katılım sağlayan spor branşları ise; Futbol, Tenis, Basketbol, Bisiklet, Yüzmedir. Avustralya Spor Komisyonu (ASC): "Avustralya Spor Enstitüsü (AIS)" aracılığı ile elit sporun gelişmesinden, "Avustralya Spor Geliştirme Grubu" ise halkın spora katılımının artmasından sorumludur. Türkiye'de spora katılımdan: "Gençlik ve Spor Bakanlı̆̆ına bağlı merkez ve taşra örgütü" ile "spor federasyonları" sorumludur. Yani, Türkiye'de spora katılımdan "devlet" sorumludur. Türkiye'de Rekreasyonel sportif aktiviteler arasında yer alan "satranç" spora katılımın ilk sırasındadır. Türkiye'de spora katılım sağlayan spor branşları ise; Futbol, Taekwando, voleybol, basketbol ve atletizm dir. İncelenen ülkelerin spora katılımlarında; satranç, yürüyüş gibi çok sayıda vatandaşın katılabildiği rekreasyonel sportif aktiviteler ilk sırada yer almıştır. Yarışma sporunda ise futbol, en çok spora katılım sağlanan spor branşıdır. Aslında bu sonuç, düzenli yapılan fiziksel aktivitelerin sağlık üzerine olan olumlu etkilerinin medya aracılığıyla kitlelere ulaşmasından kaynaklanıyor olabilir. Bu yarg1, futbol sporuna katılım için de yapılabilir. Ancak bazı ülkelerde spora katılım sağlanılan spor branşları, ülke halkı tarafından sevilen, benimsenen, toplumca kabul görmüş ve hatta toplumun kültürel özellikleriyle özdeşleşmiş olabilmektedir. Örneğin; ABD'de halk tarafından sevilen, benimsenen ve adeta ülke ile özdeşleşmiş üst düzeyde katılım sağlanılan spor branşı basketboldur.

\section{Spor Sistemleri Karşılaştırılan Ülkelerin Spor Politikalarına İlişkin Sonuçlar;}

Günümüzde ülkeler, sporu popüler bir alan olarak görmekte olup, spordan maksimum düzeyde yararlanma eğilimindedirler (Hoye ve ark., 2015). Bundan dolayıdır ki sporda gelişmiş ülkeler, sporun kitlelere yaygınlaştırılmasına önem vermektedirler (Hoye ve ark.,2017; Ak, 2017; Sunay, 2017). Almanya'da spor politikası iki yapılandırma çerçevesinde gerçekleştirilmektedir. 1.Üst düzey (elit) yarışma sporu 2.Halkın katıldığ (kitle) sporudur. $A B D^{\prime}$ de spor politikası 1.Herkes için Spor (öncelik) 2.ABD'de elit sporun gelişimidir. Organizasyonlardan özerk organizasyonlar sorumludur. Devlet müdahale etmez. ABD'de Spor, Amerikan kültürünün önemli bir parçasıdır 1.Aktif olarak, 2.Seçkin seviyede, 
3.Eğlence amaçlı, 4.Pasif seyirci olarak spora katılım fırsatları çoktur. Avustralya'da spor politikası, 1.Spora rekreatif amaçlı katılım programları önceliklidir. 2.Elit spor (ASC) aracılığı ile yaptırılır. Türkiye'de spor politikası, 1.Sağlığın korunmasına yönelik tedbirler sporun kitlelere yayılması 2.Başarılı sporcuların korunmasıdır. (Anayasa M.59) Devlet spor politikalarının uygulanmasından sorumludur. Bunu Gençlik ve Spor Bakanl1ğı, Spor Genel Müdürlüğü merkez ve taşra teşkilatları ile federasyonlar aracılığı ile gerçekleştirilir. Kanada, İngiltere, Fransa, Hollanda gibi bazı batılı ülkelerin spor politikalarının temelinde elit yarışma sporu ve fiziksel aktiviteye katılımın arttırılmasının önemli olduğu belirtilmiştir (Bergsgard ve ark.,2007; Houlihan, 2005). Dolayısıyla, incelenen ülkelerin spor politikalarına ilişkin uygulamaların, diğer bazı batılı ülkelerin uyguladıkları ulusal spor politikaları ile uyumlu olduğu söylenebilir. Öte yandan batılı ülkelerin sporun kitlelere yaygınlaştıılmasına ilişkin çabalarının nedeni, nüfuslarının büyük bir kısmının yüksek kalorili besinler tüketmesi ve obezitenin büyük bir sorun olmasından kaynaklanıyor olabilir (Finkelstein ve ark., 2005).

Sonuç olarak, Almanya'da spor bölgesel spor federasyonları, yerelde ise spor dernekleri, spor kulüpleri tarafından yönetilirken, $A B D^{\prime} d e$ sporun yönetiminde Amerikan devleti (hükümeti) müdahaleci olmamaktadır. Avustralya'da ise sporun yönetimi; paylaşımcı bir yaklaşımla gerçekleşmektedir. Karşılaştırılan ülkelerde Türkiye dışında devlet, doğrudan sporu yönetmemektedir. Spora finansal destek boyutunda ise devlet spora Almanya, Avustralya ve Türkiye'de doğrudan finansal destek sağlarken, ABD'de sporda serbest piyasa ekonomisi koşulları geçerli olup, her spor organizasyonu kendi finansmanını kendisi sağlamaktadır. Spora katılımda ülkeler arasında benzer uygulamalar saptanmıştır. Almanya'da spora katılım ağırlıklı olarak Rekreasyonel sportif aktiviteler ile Futbol, Jimnastik ve tenis ile sağlanırken, Avustralya'da da Rekreasyonel sportif aktiviteler spora katılımın ilk sirasındadır. Avustralya'da spora katılım sağlayan spor branşları ise; Futbol, Tenis ve Basketboldur. Türkiye'de de Rekreasyonel sportif aktiviteler arasinda yer alan "satranç" spora katılımın ilk sırasında yer alır. Türkiye'de spora katılım sağlayan spor branşları ise; Futbol, Tekwando ve voleyboldur. ABD'de ise spora katılım 1.Profesyonel olarak, 2.Okul ve Üniversitelerde, 3.Yerel düzeydeki spor organizasyonları ile yürüyüş en popüler sportif etkinliktir. En çok katılım gös- 
teren spor branşları ise Amerikan Futbolu, Basebol, Basketbol, Buz Hokeyi ve Futboldur. Anlaşılacağı üzere spora katılımın ilk sırasında rekreasyonel sportif aktiviteler yer almaktadır. Dolayısıyla ülkemizde rekreasyonel sportif aktiviteleri arttıracak açık ve kapalı alanların arttırılarak geliştirilmesi, sportif aktivitelerin ülke geneline yayılmasını sağlayabilecektir. Spor politikaları boyutunda ise Almanya ve ABD önceliği; Üst düzey (elit) yarışma sporu ile Halkın katıldığı (kitle) sporuna verirken, Avustralya'da öncelik, Spora rekreatif amaçlı katılım programlarıdır. Türkiye'de spor politikası sağlığın korunmasına yönelik sporun kitlelere yayılması ve başarılı sporcuların korunması şeklinde ifade edilmektedir. Bu sonuçlara göre, karşılaştırılan ülkelerde spor politikalarına yönelik önceliklerin benzer olduğu anlaşılmaktadır. Ancak ülkelerin spor politikalarındaki önceliklerinin benzer olmasına rağmen, spora katılım ve sportif başarılardaki gözle görülebilen farklılığın; ülkelerin sahip oldukları ekonomik güçlülük ile spor kültürünün yaygınlığından ve sporun yönetiminin tamamen devletin sorumluluğundan uzaklaştırıp denetleyici rol üstlenmesi, sporun yönetimini yerel yönetimler, profesyonel ve amatör spor kuruluşları ile gönüllü kuruluşlara yani toplumun sporla ilgili alt birimlerine yaygınlaştırmalarından kaynaklanıyor olabileceğinden söz edilebilir. Bu itibarla öncelikle spor aktivitelerinin yaygınlaşttrılmasına ilişkin finansal kaynağın arttırılması, kaynağın ağırlıklı olarak tesis, organizasyon ve eğitimde kullanılması sağlanmalıdır.

Sporun yaygınlaştırılmasına yönelik spor kültürünün ülkemizde oluşturulmasına yönelik çalışmaların devlet kontrolünde etkin olarak gerçekleştirilmesi sağlanmalıdır.

Sporun yönetiminde yerel yönetimler ile sivil toplum kuruluşları devletin denetim ve gözetiminde desteklenmeli, özellikle spor kulüplerinin tesisleşmelerine ve alt yapı organizasyonlarına destek verilmelidir.

Avustralya ve Almanya'daki uygulamada görüldügü gibi sporun yönetiminde devlet adına oluşturulacak ve üyelerinin spor toplumunun farklı kesimlerinden oluştuğu, bütçe uygulamaları ve çalışmalarıyla devlete karşı sorumlu "Türkiye Spor Üst Komisyonu”" oluşturulmalıdır. Ayrıca geniş tutulacak komisyona bağlı eğitim, tesisleşme, organizasyon, spor politikası, üniversitelerle işbirliği ile kulüpleşme ve alt yapı alt komisyonları gibi icracı komisyonların oluşturulması sağlanmalıdır. 


\title{
EXTENDED ABSTRACT
}

\section{Comparison of Sports Systems for Some Variables in Turkey Germany USA and Australia}

\author{
Hakan Sunay \\ Ankara University
}

The effect of sports policies on national and international sports structures, increasing the importance of sports organizations and sports economy has led to the development of management and organization understanding in this field too. The sports administrations of the countries are shaped in line with various needs and purposes in terms of their own culture, philosophy and free time evaluation of their citizens, entertainment and performance performance. Today, it is accepted that contemporary sports organization structure is affected by variables such as development levels, cultures and demographic characteristics of countries (Ekmekci, 2010). Among the countries that determined this effect and at the same time provided participation in sports and were successful in sports; Germany, USA and Australia with Turkey's "Sports Systems" is important to compare examined. Comparative research is a research method used in social sciences and aims to make comparisons between different countries or cultures. One of the difficulties of this method is that the data of different countries are not listed in the same category and defined in different categories. Therefore, international comparisons are very important in terms of seeing and determining the preferences of different systems applied in sports. In this study, athletic training systems, Organizational structure, sports financing, participation in sports and sports policy of the countries examined are examined. The aim of this study; Germany, the application for the sports system in the United States and Australia is to examine the similarities and differences with Turkey. This is a comparative sport management research. There are different approaches used in comparative research. These are horizontal, vertical, problem solving, case studies, descriptive, explanatory and evaluative approaches. In the horizontal approach, all elements of the systems separately and together are examined. When examining these ele- 
ments, all elements belonging to the period of the research are compared. In the vertical approach, the historical evolution of the system under review is monitored and leads the comparator to make some predictions about the future (Turkoglu,1998). In the descriptive approach, the literature is examined and the similarities and differences between sports systems are compared. The descriptive approach was used in this study as a vertical approach and the comparison of the sports systems of the countries mainly used the horizontal approach. In this research, documentary scanning technique was used to collect data. Documentary screening involves finding, reading, taking notes and evaluating resources for a specific purpose (Karasar, 2005; Erkus, 2005). Documentary scanning is an inevitable data collection technique for almost every research. Data collected from Turkey, Germany, USA and Australia the overall sport system and financial support for sports applied in these countries (sports financing) participation in sports, books on applied sports policy, theses, articles, magazines, has benefited from scientific sources such as development plans. In addition, data on Germany, the USA and Australia were obtained from the official web sites of these countries. In this study, "typical case sampling olan developed by Patton (1987) was used. In the analysis part of this study, quantitative methods were used (Patton, 1987). The data obtained for the research were compared for the purposes stated in the descriptive analysis approach. The information obtained during the comparisons were gathered and compiled to reveal similarities and differences as much as possible. This information was then entered into the charts. Turkey Germany four variables related to the findings obtained by the comparison of the US and Australian Sports Systems interpreted in tables. Variables related to the findings obtained:

1. The organization of the top management of sports related to the structure of sports systems

2. Sports system financial support applications of countries

3. The participation of countries in sports within the sports system

4. Sport policies of countries where sports systems are compared

Organization of the top management of sports related to the structure of sports systems: "Expert sports offices ir are effective at the state, state and local government level in Germany (Petry and Hallmann, 2013; Breuer and at.al. 2015). In the US, free market control is effective. In the 
US, the government adopts a spor non-intrusive yaklaşım approach to sport at all levels. In Australia, the management of sports takes place through a shared approach. Government and state governments provide "sponsor support ine to sports activities carried out by local organizations. The state administration of sports in Turkey is very active. 2. Sports system financial support applications of the countries: In Germany, the state provides financial support to sports in part, while in the United States, the state is not an interventionist, and the conditions of free market economy apply to financial support to sports. In fact, every organization in the USA provides its own financing. In Germany, the German government provides financial support for sports. Sports clubs use state or local sports facilities. In Australia and Turkey is supporting financially state sport.

Participation of countries in sports within the sports system: As a result of the sports policy created by the countries, it is among the priority targets to provide sports opportunities to its citizens and to enable them to play sports. Sports systems in the participation of countries in the sport; Germany's sports system; it has its own characteristics with both public and regional structure. In Germany, the state organizes high-level sports, while local governments are responsible for mass and recreational sports, while in the United States, the state is not particularly intrusive to professional sports, and promotes mass and recreational sports. The state in Australia; both through Australia's elite sports commission, while responsible for the popular participation in sports, the state in Turkey's elite and is responsible for public participation in sports.

Sport policies of the countries where sports systems are compared: Turkey is one of the few countries which place a sports constitution. In addition to the protection of the right to sport by the constitution, the sport clearly states the obligation of the state by taking part in the constitution. Furthermore, Article 4 of the Olympic Charter states that yapmak doing sports is a "human right". Every individual should have the opportunity to play sports in the right proportion with their needs. With this article, it imposes an obligation on governments to conduct sports as a state policy. The findings of the comparative countries' sports policies differ. In Germany, it is observed that the sport of high-level (elite) competition and the mass sports in which the Public participates are mana- 
ged by different responsible institutions and the sports policy is realized within the framework of these two structures. It is observed that sports policy is similar in the USA but there are differences in practice. In Australia, recreational participation in sports is a priority of sports policy. As a result, the state to manage the sport properly in Turkey, supporting and play supervisory role, providing that increase the state's sports financial support, participation in sports is intense and recreational development of sports activities for the mass sports provide elite sports orientation to take the necessary measures, sport participation in sport related with local governments taking measures to activate civil society organizations, the management of the sport in Turkey in order to reduce the burden on state or a similar purpose Turkey Sports Supreme Council will be established; a committee composed of sub-commissions, responsible to the state and supervised by the state should be established.

\section{Kaynakça / References}

Ak, A.(2017). Türk sporunda sorunlar ve çözüm önerileri. Ankara:Spor Yayınevi ve Kitabevi.

Balcı, A. (2006). Sosyal bilimlerde araştırma: Yöntem, teknik ve ilkeler. Ankara:Pegem A Yayıncilik.

Bergsgard, N.A., Houlihan, B., Mangset, P., Npdland, S.I., ve Rommetvedt, H. (2007) Sport policy: A comparative analysis of stability and change. Oxford: Butterworth-Heinemann.

Bilkent Holding (2016) Dünyada bazı ülkelerdeki sağllk ve spor kulüplerine üyelerin kulüp sayısı ülke nüfuslarına oranı. Ankara:Sport International Bilkent Holding.

Cuskelly G., Wicker, P. ve O'Brien, W. (2013) In (K. Hallmann, K. Petry ed.), Australia Comparative Sport Development Systems, Participation and Public Policy, Sports Economics, Management and Policy (p.225-236), New York:Springer Science+Business Media.

Das, S. (2019). Top 10 most popular sports in America 2019: TV Ratings https://sporteology.com/top-10-most-popular-sports-in-america/

Ekmekçi, R.(2010). Avustralya spor yönetim sisteminin incelenmesi. EJournal of New World Sciences Academy, 2B0053, 5(3), s.204-217.

Eren, E. (2001). Yönetim ve organizasyon: Çağdaş ve küresel yaklaşımlar. (5. Bsk), İstanbul:Yayınevi.

Erkuş, A. (2005). Bilimsel araştırma sarmalı. Ankara:Seçkin Yayıncılık. 
Finkelstein, E., Fiebelkorn, I., ve Wang, G. (2005) The costs of obesity among Fulltime employees. American Journal of Health Promotion, 20(1), 4551.

Fişek, K., (1998). Devlet politikası ve toplumsal yapıyla ilişkileri bakımından Dünya'da ve Türkiye'de spor yönetimi. (2. Bsm), Ankara:Bağırgan Yayınevi.

Houlihan, B. (2005) Public sector sport policy: Developing a framework for analiysis. Internat ional Review fort he Sociology of Sport, 40(2), 163-185.

Hoye, R., Nicholson, M. ve Houlihan, B. (2015) Spor ve politika meseleleri ve analizi. (C. Tınaz Çev.), (M. Bakır Çev.Ed.), İstanbul:Beta Basım Yayın, Yayın No:3234.

Karasar, N. (2005) Bilimsel araştırma yöntemleri. Ankara:Sanem Matbaacilık.

Madge, J. (1965) The tools of science. An analytical description of social science techniques. New York:Anchor Books Doubleday and Comp..

Patton, M.Q. (1987). How to use qualitative methods in evaluation. Newbury Park, CA: Sage

Petry, K. ve Hallmann, K. (2013). In (K. Hallmann, K. Petry ed.), Germany comparative sport development systems, participation and public policy, sports economics, management and policy. (p.75-86), New York:Springer Science+Business Media.

Ruseski E J. ve Razavilar N.,(2013). In (K. Hallmann, K. Petry ed.), United States comparative Sport Development Systems, Participation and Public Policy, Sports Economics, Management and Policy, (p.311-321), New York:Springer Science+Business Media

Sunay, H., (2017). Spor yönetimi. (3. Bsm), Ankara:Gazi Kitabevi.

Sutton, M., Post, D., Merkxi, G. W. Et al.(2006). Comparative education, area studies and the disciplines:First round response. Comparative Education View, 50, 1.

Kalkınma Bakanlığı. (2013). Beş yıllık kalkınma planı spor ÖIKK Raporu, Ankara.

Tews, I. H. (2006). Social stratification in sport and sport policy in the European Union, European Journal for Sport and Society, 3(2), 109-124.

Türkoğlu, A. (1998). Karşılaştırmalı eğitim: Dünya ülkelerinden örneklerle. Adana: Baki Kitabevi.

Yıldırım, A. ve Şimşek, H. (1999). Sosyal bilimlerde nitel araştırma yöntemleri. Ankara: Seçkin Yayınları.

Yüce, A ve Sunay, H. (2013).Türk sporuna ilişkin nicel gelişimin dönemsel olarak incelenmesi ve bazı ülkelerle karşılaştııılması. Ankara Üniversitesi Spor Bilimleri Fakültesi Spormetre Dergisi, 11(2), 95-103. 


\section{Kaynakça Bilgisi / Citation Information}

Sunay, H. (2019). Türkiye Almanya ABD ve Avustralya spor sistemlerinin bazı değişkenler açısından karşılaştırılması. OPUSUluslararası Toplum Araştırmaları Dergisi, 14(20), 488-513. DOI: 10.26466/opus.585855 